\title{
Clinical and Biochemical Evaluation of Facial Acanthosis Nigricans
}

\author{
Khalifa E. Sharquie'1,2*, Adil A. Noaimi1,2, Halla G. Mahmood3 ${ }^{3}$, Sameerah M. Al-Ogaily 4 \\ ${ }^{1}$ Department of Dermatology, College of Medicine, University of Baghdad, Baghdad, Iraq \\ ${ }^{2}$ Arab Board for Dermatology \& Venereology, Baghdad Teaching Hospital, Medical City, Baghdad, Iraq \\ ${ }^{3}$ Department of Clinical Biochemistry, College of Medicine, University of Baghdad, Baghdad, Iraq \\ ${ }^{4}$ Department of Dermatology, Baghdad Teaching Hospital, Medical City, Baghdad, Iraq \\ Email: *ksharquie@ymail.com, adilnoaimi@yahoo.com, halla ghazi@yahoo.com, \\ drsameraalokailimahde@yahoo.com
}

Received 10 June 2015; accepted 11 September 2015; published 14 September 2015

Copyright (C) 2015 by authors and Scientific Research Publishing Inc.

This work is licensed under the Creative Commons Attribution International License (CC BY).

http://creativecommons.org/licenses/by/4.0/

(c) (i) Open Access

\section{Abstract}

Background: Acanthosis nigricans is a well known cause of facial melanosis in Iraqi males and usually it is a part of ordinary acanthosis nigricans. It is commonly associated with many metabolic derangements. Objectives: To evaluate cases of acanthosis nigricans of the face for all metabolic disturbances including fasting blood sugar, fasting serum insulin, total cholesterol, triglyceride, growth hormone and serum leptin. Patients and Methods: Twenty seven cases of acanthosis nigricans of the face were included in this case descriptive, clinical and biochemical study. This was conducted in Department of Dermatology-Baghdad Teaching Hospital and Department of Clinical Biochemistry, College of Medicine, Baghdad, Iraq during the period from November 2012-August 2014. It consisted of 26 males and one female, their ages ranged from 16 - 58 (39 \pm 4.9$)$ years. The diagnosis was established by clinical and histopathological evaluation. Sharquie's ANSI scoring of acanthosis nigricans of face was carried out for all patients, also body mass index was assessed. Biochemical evaluation was carried out for all patients including total cholesterol, triglyceride, fasting blood sugar and insulin, insulin resistance, growth hormone and leptin enzyme immunoassay. Twenty seven healthy control non obese individuals with comparable ages and gender were assessed for all tests. Results: Biochemical results showed that fasting blood glucose, fasting serum insulin, insulin resistance, fasting serum triglyceride, total cholesterol, growth hormone and serum leptin were statistically significantly high in patients with acanthosis nigricans of the face in comparison with control individuals and all were positively correlated with the scoring of acanthosis nigricans of the face apart from high density lipoprotein was negatively correlated. Conclusion: Acanthosis nigricans of the face is a good marker for the associated metabolic diseases and these metabolic changes were statistically significantly correlated with the severity of acanthosis nigricans.

"Corresponding author.

How to cite this paper: Sharquie, K.E., Noaimi, A.A., Mahmood, H.G. and Al-Ogaily, S.M. (2015) Clinical and Biochemical Evaluation of Facial Acanthosis Nigricans. Journal of Cosmetics, Dermatological Sciences and Applications, 5, 231-237.

http://dx.doi.org/10.4236/jcdsa.2015.53028 


\section{Keywords}

\section{Acanthosis Nigricans, Face, Sharquie's Ansi Scoring, Facial Melanosis, Biochemical Changes}

\section{Introduction}

Acanthosis nigricansis (AN) a skin disease characterized by hyperpigmented, thickened, verrucous plaques with a velvety texture typically symmetrical in distribution. It usually involves intertriginous areas including: neck, axillae, groin, antecupital and popliteal fossae, knuckles and umbilicus; occasionally it involves the mucosa such as oral, esophageal, pharyngeal, laryngeal, conjunctival, and anogenital mucosa [1]. The earliest changes in acanthosis nigricans of the face are usually dryness, pigmentation and roughness of the skin, which in affected area is gray-brown or black [1]. The hyperpigmentation is later accompanied by hypertrophy, increased skin marking, and velvety texture. The most commonly involved locations are the forehead, temples, nasolabial folds and cheeks [2]. Facial melanosis although is commonly caused by acanthosis nigricans of the face among adult males [3] but unfortunately was not reported and documented in the medical literatures until Sharquie et al. 2014, 2015 published their work. This study showed that acanthosis nigricans of the face has the same clinical and histopathological features of acanthosis of neck and axillae mainly pigmentation of the skin, thickening with or without velvety appearance and acanthosis with or without papillomatosis together with epidermal and dermal melanosis [2].

Acanthosis nigricans has a variety of causes but the likely common mechanism is stimulation of tyrosine kinase growth factor receptor signaling pathways in epidermis [4]. In insulin resistance syndromes, high levels of circulating insulin directly or indirectly activate the insulin-like growth factor 1 receptor (IGF1R) [5]. Insulin resistance due to obesity underlies the hyperinsulinaemia in obesity-associated acanthosis nigricans [6] [7]. An elevated fasting blood insulin level confirms the presence of hyperinsulinaemia underling the diagnosis of atypical acanthosis nigricans [8]. In malignant acanthosis nigricans, tumor deriver growth factors, in particular transforming growth factor- $\alpha$, acting through the epidermal growth factor receptor (EGFR) is presumed, although anti-insulin receptor antibodies have also been implicated [9].

The metabolic disorder parameters like fasting blood sugar, fasting serum insulin, total cholesterol, triglyceride, serum growth hormone and serum leptin were not evaluated before. So the aim of present work is to assess these metabolic markers and to be correlated with the severity of acanthosis nigricans of the face.

\section{Patients and Methods}

This case descriptive, clinical and biochemical study was conducted in the Department of Dermatology-Baghdad Teaching Hospital and Department of Clinical Biochemistry, College of Medicine, Baghdad, Iraq during the period from November 2012 to August 2014. Twenty seven patients were enrolled in this study 26 males and 1 female. The nature and aim of this study were explained for each patient. Formal consent was taken from them before this study and photographs were taken. Also, the ethical approval was given by the Scientific Council of Dermatology \& Venereology-Iraqi Board for Medical Specializations.

Clinical and histopathological study of acanthosis nigricans of the face of these patients were already published [2].

Body mass index for all patients were calculated in addition the atherogenic co-efficiency, atherogenic index plasma and cardiac risk ratio were assessed.

Color photographs for all patients were performed by 8 megapixels camera of mobile Samsung Galaxy Note II, in the same place and distance with fixed illumination.

Sharquie's ANSI scoring [2] was carried out for all patients regarding the followings:

Score 1 = Light brown;

Score 2 = Brown;

Score 3 = Dark brown;

Score 4 = Black.

1) Texture: Scoring from $0-3$

Score $0=$ No thickening; 
Score 1 = Mild thickening;

Score 2 = Moderate thickening;

Score 3 = Severe thickening.

2) Percentage of the total area involved, this was measured by using transparent square paper. By this method the acanthosis nigricanc and the total surface areas were measured accurately by square centimeters, then the percentage of the acanthosis nigricansarea relative to the total area of the same region was measured and scoring was done as follows:

a) Forehead:

Score $1=1 \%-25 \%$;

Score $2 \geq 25 \%-50 \%$;

Score $3 \geq 50 \%$ - 75\%;

Score $4 \geq 75 \%$.

b) Cheek:

Score $1=1 \%$ - 25\%;

Score 2 $\geq 25 \%$ - 50\%;

Score $3 \geq 50 \%$ - 75\%;

Score $4 \geq 75 \%$.

c) Nasolabial folds:

Score $1=1 \%-25 \%$;

Score $2 \geq 25 \%$ - 50;

Score $3 \geq 50 \%$ - 75\%;

Score $4 \geq 75 \%$.

d) Temporal area:

Score $1=1 \%-25 \%$;

Score 2 $\geq 25 \%$ - 50\%;

Score $3 \geq 50 \%$ - 75\%;

Score $4 \geq 75 \%$.

The scoring for each area were done separately including: forehead, right temporal, left temporal, right cheek, left cheek, right nasolabial fold and left nasolabial fold for all patients.

The ANSI score was calculated by the following equation:

$$
\begin{aligned}
\mathbf{A N S I}= & (\mathbf{D F}+\mathbf{T F}+\mathbf{A F})+(\mathbf{D T R}+\mathbf{T T R}+\mathbf{A T R})+(\mathbf{D T L}+\mathbf{T T L}+\mathbf{A T L})+(\mathbf{D C R}+\mathbf{T C R}+\mathbf{A C R}) \\
& +(\mathbf{D C L}+\mathbf{T C L}+\mathbf{A C L})+(\mathbf{D N R}+\mathbf{T N R}+\mathbf{A N R})+(\mathbf{D N L}+\mathbf{T N L}+\mathbf{A N L}) .
\end{aligned}
$$

where $\mathrm{D}$ is darkness, $\mathrm{T}$ is thickness, A is area, F is forehead, TR is right temporal, TL is left temporal, CR is right cheek, CL is left cheek, NR is right nsolabial, NL is left nasolabial [2].

The following biochemical tests were carried out: fasting blood sugar (FBS), fasting insulin, total cholesterol, triglyceride which determined by enzymatic methods, growth hormone and serum leptin enzyme immunoassay for the quantitative determination in human serum were used. DRG international Inc. USA is done by ELISA test and the results were correlated with the severity of acanthosis nigricans (Sharquie's ANSI score) using coefficient correlation.

Twenty seven healthy control individuals with age and gender matching with the patients of acanthosis nigricans of the face were studied for the same biochemical blood changes.

Data were statistically described in terms of range, mean, standard deviation $( \pm S D)$, mode of frequencies (number of cases) and relative frequencies (percentages). Comparison between investigations of patients and controlled individuals was done using Chi square $\left(\mathrm{x}^{2}\right)$ test. A probability value (p value) less than 0.05 was considered significant. All statistical calculations were done using computer programs SPSS ver. 20 (Statistical Package for the Social Science; SPSS Inc. Chicago, IL, USA).

\section{Results}

Twenty seven patients with acanthosis nigricans of the face were included in this study, 26 (96.6\%) males and 1 (3.3\%) female, with a male to female ratio was 26:1. Their ages ranged from 16 - 58 years with a mean \pm SD of $39 \pm 4.9$ years. The third and fourth decades of life were the commonest age groups affected. The duration of the 
disease ranged from 1 - 8 years with a mean \pm SD of $3.34 \pm 5.67$ years. All patients had bilateral symmetrical distribution of acanthosis nigricans on the face (Figure 1) in addition to acanthois nigricans of neck and axillae. No patients with underling malignancies, clinical diabetes or other important medical conditions were noted.

Twenty seven healthy control were assessed, 25 males and 2 females, their ages ranged from 18 - 56 years with a mean \pm SD of $40 \pm 2.93$ years. the body mass index was ranged from $23-29.3$ with a mean \pm SD of $27 \pm$ 0.93 (Table 1).

Normal weight was seen in 4 (13.3\%) patients while overweight seen in 10 (33.3\%) patients, and obese in 16 (53.3\%) patients. The body mass index (BMI) ranged from 24.1 - 38 with a mean \pm SD of $32.33 \pm 0.72$. So BMI was found to be highly significant elevated in patients with acanthosis nigricans of the face in comparison with healthy control individuals with $\mathrm{P}$ value $=0.00545$.

Fasting blood sugar $(\mathrm{P}$ value $=0.00141)$, fasting serum insulin $(\mathrm{P}$ value $=0.00150)$, Homa-insulin resistance $(\mathrm{P}$ value $=0.00157)$, growth hormone $(\mathrm{P}$ value $=0.061446)$, Serum leptin $(\mathrm{P}$ value $=0.01550)$, total cholesterol $(\mathrm{P}$ value $=0.0014)$ and triglyceride $(\mathrm{P}$ value $=0.0032)$ were statistically significantly elevated in comparison with healthy control. Also, cardiac risk ratio $(\mathrm{CRR})(\mathrm{P}$ value $=0.001)$ and atherogenic coefficient $(\mathrm{AC})(\mathrm{P}$ value $=0.005)$ and atherogenic index plasma $($ AIP $)(P$ value $=0.003)$ were highly significantly elevated $($ Table 1$)$.

Sharquie's ANSI score was ranged from 4 - 62 and was positively correlated with the following parameter: serum insulin ( $r=0.925)$, total cholesterol $(r=0.968)$, AIP ( $r=0.95), A C(r=0.976)$, serum leptin $(r=0.889)$ growth hormone $(r=0.945)$ and fasting blood sugar $(\mathrm{r}=0.943)$, while there was negative correlation with HDL $(r=0.913)$ (Figures 2-6). $(r=$ coefficient correlation).

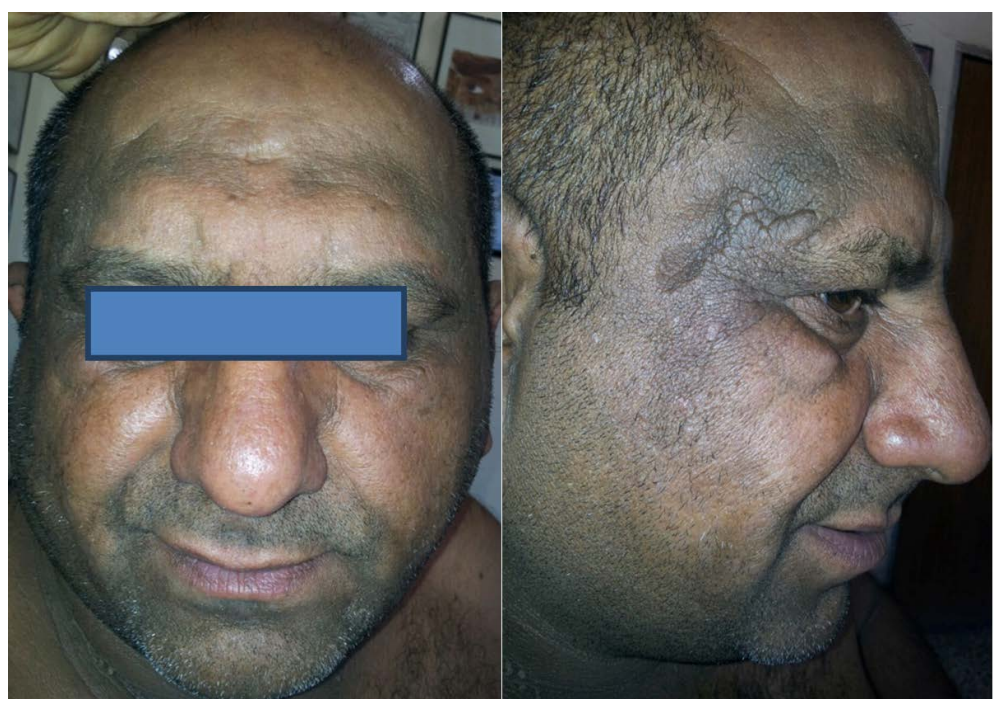

Figure 1. Bilateral symmetrical distribution of acanthosis nigricans on the face.

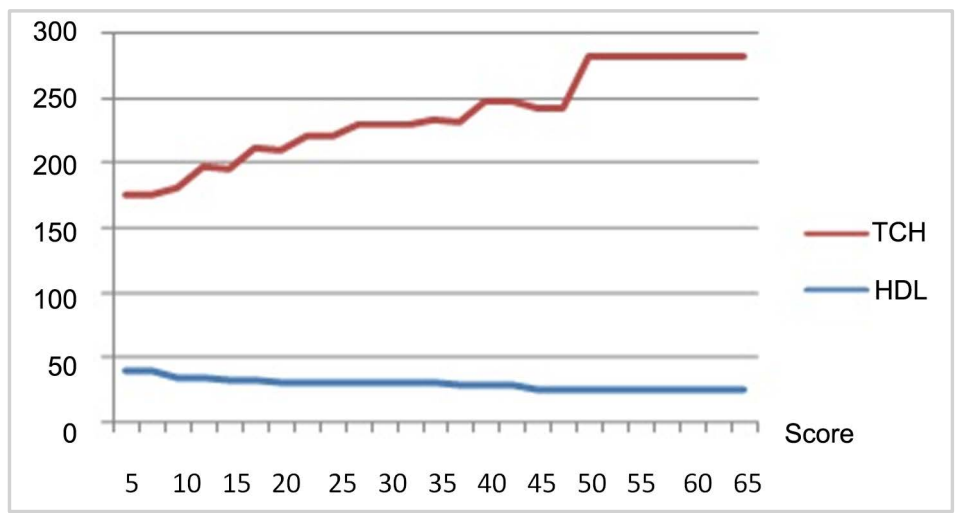

Figure 2. Showing the correlation between ANSI score \& HDL \& TCH levels. 


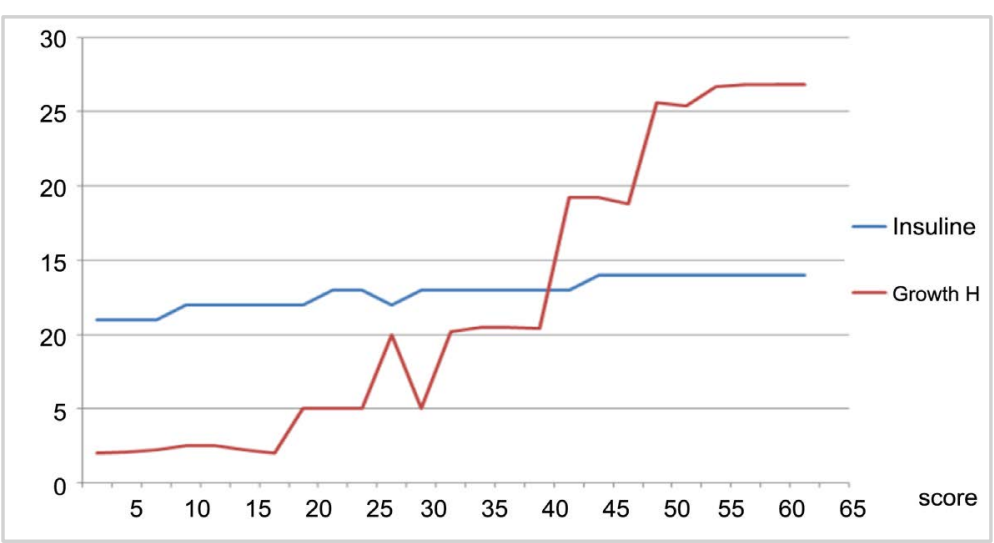

Figure 3. Showing the correlation between ANSI score \& insulin \& growth hormone levels.

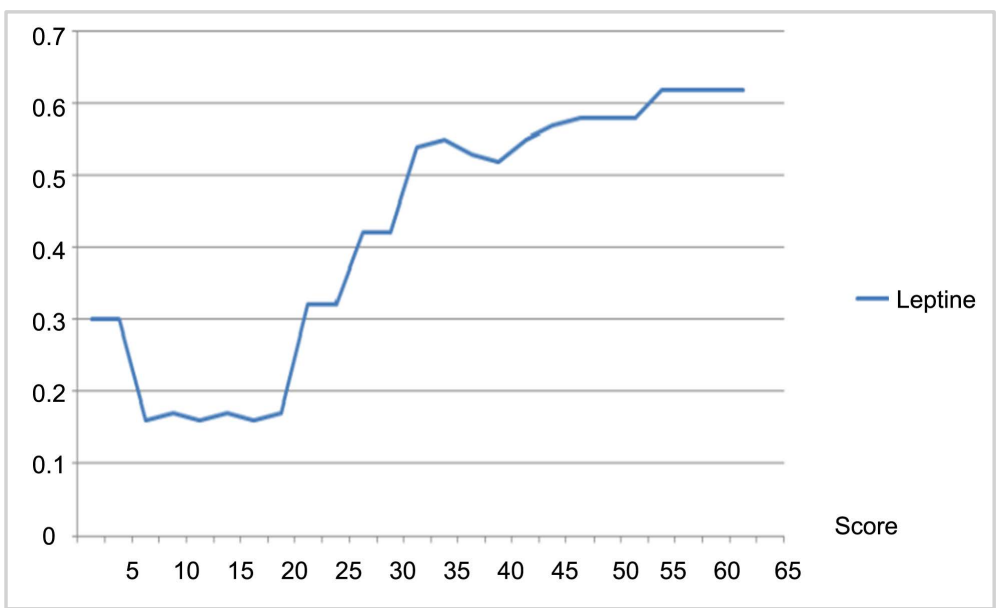

Figure 4. Showing the correlation between ANSI score \& leptin level.

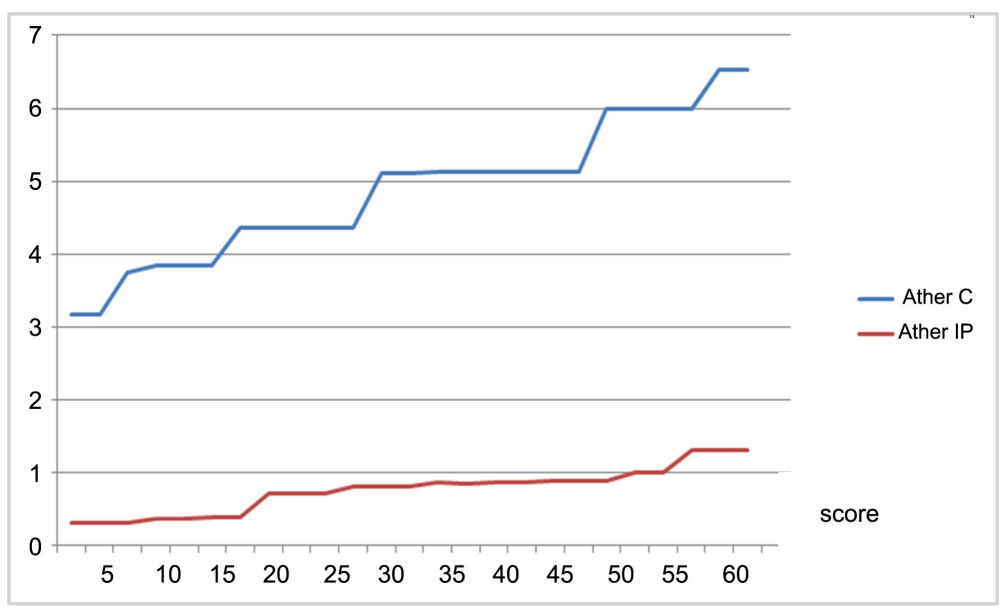

Figure 5. Showing the correlation between ANSI score \& AC \& AIP levels.

\section{Discussion}

Acanthosis nigricans is commonly associated with obesity and might be associated with many metabolic disturbances like diabetes mellitus, elevated cholesterol and HBA1c [2]. No malignancies or drugs induced acanthosis 


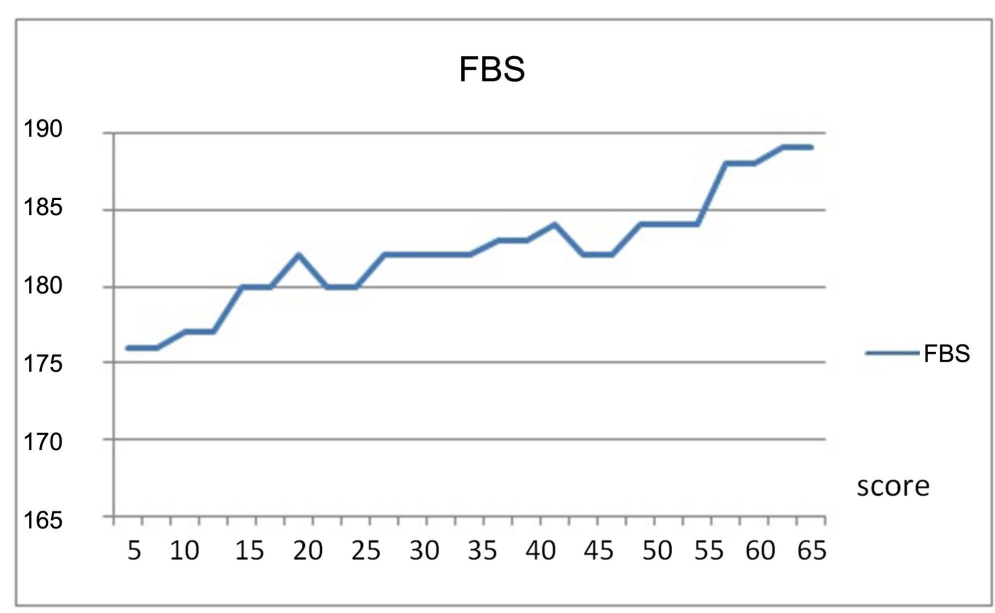

Figure 6. Showing the correlation between ANSI score \& FBS levels.

Table 1. The result of fasting blood sampling from 27 patients with acanthosis nigricans of the face in comparison with 27 healthy controls.

\begin{tabular}{cccc}
\hline & Control & Patients & P-value \\
\hline Age & $40 \pm 2.93$ & $39 \pm 4.97$ & NS \\
BMI $\left(\mathrm{Kg} / \mathrm{m}^{2}\right)$ & $27 \pm 0.93$ & $32.33 \pm 0.72$ & HS \\
FBG $(\mathrm{mg} / \mathrm{dl})$ & $96.4 \pm 3$ & $180.3 \pm 2.16$ & HS \\
Insulin $(\mu \mathrm{lU} / \mathrm{ml})$ & $10.76 \pm 0.4$ & $12.3 \pm 0.9$ & HS \\
Homa-IR & $2.57 \pm 0.1$ & $5.46 \pm 0.36$ & HS \\
Leptin (mg/dl) & $0.38 \pm 0.25$ & $0.479 \pm 0.07$ & $\mathrm{~S}$ \\
CRP (mg/dl) & $2.078 \pm 0.432$ & $1.68 \pm 0.79$ & $\mathrm{~S}$ \\
GH (ng/ml) & $5.66 \pm 0.10$ & $13.16 \pm 9.43$ & $\mathrm{~S}$ \\
TC (mg/dl) & $187.3 \pm 10.78$ & $191.75 \pm 34.34$ & HS \\
TG (mg/dl) & $121 \pm 9.55$ & $223 \pm 44$ & HS \\
HDL-C (mg/dl) & $49.8 \pm 6.78$ & $33.12 \pm 3.9$ & HS \\
CRR & $3.80 \pm 0.31$ & $5.70 \pm 1.21$ & HS \\
AC & $2.80 \pm 0.31$ & $4.82 \pm 1.03$ & HS \\
AIP & $0.39 \pm 0.03$ & $0.85 \pm 0.24$ & HS \\
\hline
\end{tabular}

nigricans were included in the present work.

The present study showed that Sharquie's ANSI score of acanthosis nigricans of the face was well correlated with the severity of acanthosis nigricans and body mass index. This score was also statistically significantly correlated with the following biochemical changes: FBS, fasting insulin, total cholesterol, triglyceride, growth hormone and serum leptin.

The present work also showed patients with acanthosis nigricans of the face had hyperinsulinemia and insulin resistance and this explain the pathogenesis of acanthosis nigricans like thickening of the epidermis and increased melanin deposition as was similarly reported about ordinary acanthosis nigricans [10], similarly this study also demonstrated elevated growth hormone in majority of cases of acanthosis nigricans of the face and this hormone also increase the activity of fibroblast and keratinocyte and play a role in pathogenesis of acanthosis nigricans. Serum leptin also elevated in majority of patients in the present study and this might explain the increased obesity among patients with acanthosis nigricans [11]. 
Total cholesterol and triglyceride were significantly elevated in majority of patients with decreased high density lipoprotein that lead to increase in cardiac risk ratio, atherogenic coefficient andatherogenic index plasma. These findings are very important as you can judge the changes in these parameter just by looking at the acanthosis nigricans of the face. To the best of our knowledge these findings are for the first time to be reported.

\section{Conclusion}

In conclusion, acanthosis nigricans of the face is an important cause of facial melanosis among Iraqi males where its clinical pictures and associated manifestations were similar to acanthosis nigricas of the body. Also, acanthosis nigricans of the face is a marker for many metabolic and biochemical changes in blood like elevated fasting blood sugar and lipid. Sharquie's ANSI scoring of acanthosis nigricans of the face was positively correlated with all biochemical changes.

\section{Disclosure}

This study was an independent study and not funded by any drug companies.

\section{References}

[1] Houp, K.R. and Crus, P.D. (1999) Acanthosis Nigricans. In: Fitzpatrick, T.B., Freedberg, I.M., Eison, A.Z., Wolff, K., Austen, K.F., Gold Smith, L.A. and Katz, S.I., Eds., Fitzpatrick's Dermatology in General Medicine, 5th Edition, McGraw-Hill Book Company, New York, 40, 244-252.

[2] Sharquie, K.E., Noaimi, A.A. and Al-Ogaily, S.M. (2015) Acanthosis Nigricans as a Cause of Facial Melanosis (Clinical and Histopathological Study). IOSR Journal of Dental and Medical Science, 14, 84-90.

[3] Sharquie, K.E. and Noaimi, A.A. (2014) Gazelle Eye like Facial Melanosis (Clinico-Histopathological Study). Journal of Pigmentary Disorders, 2, 111.

[4] Judge, M.R., Mclean, W.H.I. and Munro, C.S. (2010) Disorder of Keratinization. Tony B. Stephen B. Rook Textbook of Dermatology, 8th Edition, Wiley-Blackwell, 119-120.

[5] Torley, D., Bellus, G.A. and Munro, C.S. (2002) Genes, Growth Factors and Acanthosis Nigricans. British Journal of Dermatology, 147, 1096. http://dx.doi.org/10.1046/j.1365-2133.2002.05150.x

[6] Skiljevic, D.S., Nikolic, M.M. and Jakovljevic, A. (2001) Generalized Acanthosis Nigricans in Early Childhood. Pediatric Dermatology, 18, 213-218. http://dx.doi.org/10.1046/j.1525-1470.2001.018003213.x

[7] Kahn, C.R., Flier, J.S. and Bar, R.S. (1999) The Syndromes of Insulin Resistance and Acanthosis Nigricans: Insulin Receptor Disorders in Man. New England Journal of Medicine, 294, 739-754. http://dx.doi.org/10.1056/NEJM197604012941401

[8] Haase, I. and Hunzelmann, N. (2002) Activation of Epidermal Growth Factor Receptor, ERK Signaling Correlates with Suppressed Differentiation in Malignant Acanthosis Nigricans. Journal of Investigative Dermatology, 118, 891-893. http://dx.doi.org/10.1046/j.1523-1747.2002.17631.x

[9] Cruz, P.D.G. and Hud, J.A.J. (1992) Excess Insulin Binding to Insulin-Like Growth Factor Receptor: Proposed Mechanism for Acanthosis Nigricans. Journal of Investigative Dermatology, 98, 825-855. http://dx.doi.org/10.1111/1523-1747.ep12462293

[10] Habif, T.P. (2004) Cutaneous Manifestations of Internal Disease: Acanthosis Nigricans. Clinical Dermatology: A Color Guide to Diagnosis and Therapy, 4th Edition, Mosby Company, Philadelphia, 10, 900-901.

[11] Considine, R.V. Sinha, M.K., Heiman, M.L., Kriauciunas, A., Stephens, T.W., Nyce, M.R., Ohannesian, J.P., Marco, C.C., Mckee, L.J., Bauer, T.L. and Caro, J.F. (1996) Serum Immunoreactive-Leptin Concentration in Normal-Weight and Obese Humans. New England Journal of Medicine, 334, 292-295. http://dx.doi.org/10.1056/NEJM199602013340503 